\title{
Crescimento, produtividade e qualidade de fibra de algodão colorido influenciados pela população de plantas ${ }^{1}$
}

\author{
Gibran da Silva Alves ${ }^{2}$, Francilene de Lima Tartaglia ${ }^{2 *}$, Jhonatas Cortes Rosa ${ }^{3}$, Matheus Martins Ferreira ${ }^{2}$, \\ Jackeline Silva de Carvalho ${ }^{4}$, Wagner Walker de Albuquerque Alves ${ }^{5}$
}

$10.1590 / 0034-737 X 201764010010$

\section{RESUMO}

O objetivo deste trabalho foi avaliar o crescimento, a produtividade e as características de fibra de algodão colorido em diferentes populações de plantas. Foram utilizados os delineamentos experimentais em blocos ao acaso, em esquema fatorial 5 x 8 para as variáveis de crescimento e unifatorial, para os componentes de produção, com quatro repetições. Os fatores considerados foram populações de plantas $\left(125.000 ; 41.667 ; 25.000 ; 17.857\right.$; e 13.889 plantas ha $\left.^{-1}\right)$ e períodos de avaliação $(15 ; 30 ; 45 ; 60 ; 75 ; 90 ; 105$; e 120 dias após a emergência). Para as populações de plantas, utilizaram-se cinco diferentes densidades, de $10 ; 3,3 ; 2 ; 1,42$; e 1,1 plantas por metro. As unidades experimentais apresentaram $4 \mathrm{~m}$ de largura, $6 \mathrm{~m}$ de comprimento e seis linhas de plantas, espaçadas de 0,80 metros entre linhas, sendo as duas centrais a área útil. Avaliaram-se altura de planta, diâmetro de caule, área foliar, número de capulhos por $\mathrm{m}^{2}$, número de capulhos por planta, massa de frutos por planta, produtividade de algodão em caroço, produtividade de fibra e características tecnológicas de fibra. $\mathrm{O}$ aumento da população de plantas reduz o diâmetro de caule, a altura de plantas, a área foliar, o número de frutos e a massa de frutos por planta, mas não influencia o número de capulhos por $\mathrm{m}^{2}$. As maiores produtividades de algodão em caroço e de fibra de algodão foram obtidas nas populações de $71.471 \mathrm{e}$ 72.964 plantas ha $^{-1}$, respectivamente. As características tecnológicas de fibra, índice de fibras curtas, resistência à ruptura e o índice de fiabilidade são melhoradas com o cultivo de 125.000 plantas ha $^{-1}$.

Palavras-chave: Gossypium hirsutum; competição intraespecífica; densidade de plantas.

\section{ABSTRACT}

\section{Growth, yield, and fiber quality of colored cotton are influenced by the plant population}

The objective of this study was to evaluate the growth, productivity, and fiber quality of colored cotton in different plant populations. We adopted the design in randomized blocks, in a factorial scheme of $5 \times 8$ for the growth variables and unifactorial for the production components, with four replications. The factors were plant populations (125,000; 41,$667 ; 25,000 ; 17,857$; and 13,889 plants $\left.^{-1} \mathrm{a}^{-1}\right)$ and evaluation periods $(15 ; 30 ; 45 ; 60 ; 75 ; 90 ; 105$, and 120 days after emergence). Five different plant densities were used to compose the plant populations: 10, 3.3, 2, 1.42, and 1.1 plants per meter. The experimental units had $4 \mathrm{~m}$ wide, $6 \mathrm{~m}$ long, and six plant lines spaced $0.80 \mathrm{~m}$ between rows and the two central lines were the useful area. The plant height, stem diameter, leaf area, number of bolls per $\mathrm{m}^{2}$, number of bolls per plant, weight of fruits per plant, productivity of seed cotton, lint yield, and technological characteristics of fiber were evaluated. The increase in plant population reduced the stem diameter, plant height, leaf area, the number of fruits, and

\footnotetext{
Submetido em 11/02/2014 e aprovado em 16/12/2016.

${ }_{1}^{1}$ Parte do trabalho de conclusão de curso da segunda autora.

22 Universidade Federal do Pampa, Itaqui, Rio Grande do Sul, Brasil. gibranalves@yahoo.com.br; fran.tartaglia@yahoo.com.br; math.ferreira10@yahoo.com.br

${ }^{3}$ Centro Universitário Luterano de Ji-Paraná, Ji-Paraná, Rondônia, Brasil. jhonatascortes@ @otmail.com

${ }^{4}$ Campos do Júlio, Mato Grosso, Brasil. Jackeline1803@terra.com.br

${ }^{5}$ Universidade Federal de Rondônia, Campus Rolim de Moura, Rolim de Moura, Rondônia, Brasil. wagnerwaa@gmail.com

*Autora para correspondência: fran.tartaglia@yahoo.com.br
} 
weight of fruits per plant, but did not influence the number of bolls per $\mathrm{m}^{2}$. The highest yield of seed cotton and cotton fiber were obtained at populations of 71,471 and 72,964 plants ha ${ }^{-1}$, respectively. The technological characteristics of

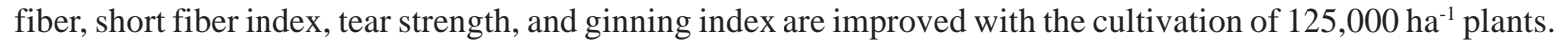

Key words: Gossypium hirsutum; intraspecific competition; plant density.

\section{INTRODUÇÃO}

O algodão colorido (Gossypium hirsutum L.) pertence à família das malváceas, espécie com hábito de crescimento indeterminado, na qual crescimento vegetativo, aparecimento de gemas reprodutivas, florescimento, crescimento e maturação de frutos ocorrem simultaneamente (Rosolem, 2007).

Essa espécie surge no mercado como uma opção de renda e de diversificação para agricultura familiar, visto que apresenta preço diferenciado no mercado, em relação ao do algodão de fibra branca. Além dessa importância social, a utilização do algodão naturalmente colorido evita a poluição ambiental, uma vez que dispensa a etapa de tingimento, a qual apresenta resíduos tóxicos que, se eliminados sem o devido tratamento, poluem o meio ambiente (Guaratini \& Zanoni, 2000).

A cultura do algodoeiro tem seu desenvolvimento e produtividade afetados por diversos fatores. Dentre esses, um de fácil manipulação e que exerce grande influência é a população de plantas, pois a forma como as plantas são dispostas na lavoura influencia a absorção de luz, nutrientes e água e, desse modo, pode-se alterar o crescimento da planta, a partição de biomassa, a distribuição de frutos e o potencial produtivo (Stephenson et al., 2011; Kaggwa-Asiimwe et al., 2013).

O aumento da população de plantas pode contribuir para fechamento rápido do dossel, o que, por sua vez, reduz a incidência de plantas daninhas e a evaporação da água (Darawsheh et al., 2009) e melhora a interceptação de luz. Por outro lado, as baixas populações de plantas tendem a proporcionar plantas mais altas e a formação de ramos frutíferos mais longos, dificultando a colheita mecanizada (Pereira et al., 2011). Portanto, a definição de uma população ideal de plantas é uma forma de maximizar a produtividade.

Com o surgimento de novos cultivares de algodão, torna-se importante a realização de trabalhos, em diversos locais, com diferentes tipos de clima e de solo, visando a determinar populações de plantas que proporcionem adequado desenvolvimento, maiores produtividades e aproveitamento máximo da área.
Rondônia situa-se em uma região pouco estudada cientificamente, carente de tecnologias que permitam diversificar a produção agrícola e gerar alternativas de cultivo e de aumento do ganho econômico para o produtor rural. Diante da importância da cultura, da falta de tecnologias e de novas alternativas de cultivo, o objetivo deste trabalho foi avaliar o crescimento, a produtividade e as características tecnológicas de fibra do algodão colorido BRS Safira, em diferentes populações de plantas.

\section{MATERIAL E MÉTODOS}

O experimento foi desenvolvido no ano agrícola de 2011, na área experimental do Centro Universitário Luterano de Ji-Paraná, município de Ji-Paraná, RO, a 1052'53" S e 61³0'45" O, com altitude média de 159 m. O clima da região, segundo a classificação de Köppen, é do tipo Awi, com estação relativamente seca nos meses de junho a agosto (Bezerra, 2010).

A área experimental apresenta solo classificado como Cambissolo Húmico, com horizonte superficial espesso e de coloração escura (Santos et al., 2013). Antes da semeadura, foram coletadas amostras de solo, na profundidade de $0-20 \mathrm{~cm}$, e caracterizadas quimicamente: $\mathrm{pH}\left(\mathrm{H}_{2} \mathrm{O}\right)=$ 6,$1 ;$ M.O. $=1,7$ dag kg; $\mathrm{P}=0,9 \mathrm{mg} \mathrm{dm}^{-3} ; \mathrm{K}=0,18 \mathrm{cmol}_{\mathrm{c}} \mathrm{dm}^{-}$ 3. $\mathrm{Ca}=2,9 \mathrm{cmol} \mathrm{dm}^{-3} ; \mathrm{Mg}=1,5 \mathrm{cmol}_{\mathrm{c}} \mathrm{dm}^{-3} ; \mathrm{H}+\mathrm{Al}=3 \mathrm{cmol}_{\text {c }}$ $\mathrm{dm}^{-3} ; \mathrm{SB}=4,58 \mathrm{cmol}_{\mathrm{c}} \mathrm{dm}^{-3} ; \mathrm{CTC}=7,58 \mathrm{cmol}_{\mathrm{c}} \mathrm{dm}^{-3} \mathrm{e} \mathrm{V}=$ $60,42 \%$.

No preparo do solo foi efetuada uma aração e duas gradagens. Na semeadura, a adubação foi efetuada segundo a análise de solo, aplicando-se 20-100-70 kg ha-1 de nitrogênio $(\mathrm{N})$, fósforo $\left(\mathrm{P}_{2} \mathrm{O}_{5}\right)$ e potássio $\left(\mathrm{K}_{2} \mathrm{O}\right)$, nas formas de ureia, superfosfato simples e cloreto de potássio, respectivamente. A adubação de cobertura foi parcelada, metade aos 25 e metade aos 45 dias após a emergência (DAE) das plantas, aplicando-se $60 \mathrm{~kg} \mathrm{ha}^{-1} \mathrm{de} \mathrm{N}$, na forma de sulfato de amônio, e $30 \mathrm{~kg} \mathrm{ha}^{-1}$ de $\mathrm{K}_{2} \mathrm{O}$, na forma de cloreto de potássio. Com pulverizador costal, foi realizada uma única aplicação de solução de ácido bórico, $\mathrm{H}_{3} \mathrm{BO}_{3}$, com 17,48\% de boro, na proporção de $1 \mathrm{~kg} \mathrm{ha}^{-1}$.

Utilizou-se o sistema de irrigação por aspersão em linha, em que o controle da lâmina foi obtido em testes no 
campo, a partir dos resultados da precipitação dos aspersores representativos nas faixas em estudo.

Foi utilizado o cultivar de algodão colorido BRS Safira, que apresenta fibra de coloração marrom escura ou marrom telha, lançado no ano de 2005. A semeadura foi realizada manualmente, no início do mês de julho, com a finalidade de estabelecer as populações de plantas de acordo com os tratamentos definidos previamente e, para isso, aos 25 DAE foi realizado o desbaste.

A eliminação das plantas daninhas foi feita de forma manual, por meio de capinas, que mantiveram a cultura livre de competição até a colheita. O manejo fitossanitário foi realizado a fim de controlar pragas e doenças (pulgão, percevejo manchador e mancha de ramulária), de acordo com a necessidade, seguindo-se as recomendações técnicas para a cultura.

Os delineamentos experimentais foram em bloco ao acaso, em esquema fatorial 5 x 8, para as variáveis de crescimento e unifatorial, para os componentes de produção, com quatro repetições. Os fatores foram compostos por populações de plantas $(125.000 ; 41.667 ; 25.000 ; 17.857$; e 13.889 plantas ha $^{-1}$ ) e períodos de avaliação $(15 ; 30 ; 45$; 60; 75; 90; 105; e 120 DAE).

Para compor as populações de plantas, utilizaram-se cinco diferentes densidades de plantas na linha de semeadura, $10 ; 3,3 ; 2 ; 1,42$; e 1,1 plantas por metro. As unidades experimentais apresentaram $4 \mathrm{~m}$ de largura, $6 \mathrm{~m}$ de comprimento e seis linhas de plantas, espaçadas de 0,80 metros entre linhas, sendo as duas centrais a área útil.

As avaliações de crescimento foram realizadas quinzenalmente, por um período de 120 dias, nas mesmas seis plantas identificadas na área útil da parcela, até o fim do experimento. A altura de plantas foi medida com trena milimetrada, a partir do colo até a extremidade final da planta. $\mathrm{O}$ diâmetro caulinar foi medido com paquímetro digital, aproximadamente $4,0 \mathrm{~cm}$ acima da superfície do solo.

A área foliar foi estimada a partir da equação proposta por Grimes \& Carter (1969), que constou em medir o comprimento da nervura principal de cada folha com uma régua milimetrada e, em seguida, aplicar a Equação 1, em que a soma da área de todas as folhas permitiu obter a área foliar da planta:

$\mathrm{Y}=0,4322 \mathrm{X}^{2,3002}$

em que Y é a área foliar por planta e X é o comprimento da nervura principal da folha de algodão. Os dados de área foliar foram transformados pela fórmula $\sqrt{\mathrm{x}+1}$.

A colheita foi realizada manualmente em três etapas: primeiro, aos 120 DAE, quando $50 \%$ em média dos capulhos estavam totalmente abertos, e mais duas vezes (uma vez por semana), colhendo-se os capulhos na área útil de cada parcela. Os capulhos foram levados para o laboratório de sementes, a fim de se determinarem as variáveis de produção.

O número de capulhos por $\mathrm{m}^{2}$ foi determinado pelo número de capulhos colhidos na área útil convertida para $1,0 \mathrm{~m}^{2}$. O número de capulhos por planta foi determinado pelo número de capulhos colhidos na área útil da parcela, dividido pelo número de plantas na área. A massa de frutos por planta foi determinada pela razão entre a massa total de frutos colhida na área útil, dividida pelo número de plantas naquela área.

A produtividade de algodão em caroço foi determinada pela massa de caroço mais fibra, colhidos em cada área útil e posteriormente convertida para $\mathrm{kg} \mathrm{ha}^{-1}$. A produtividade de fibra de algodão foi determinada pela massa de fibra colhida na área útil de cada parcela, após a remoção das sementes, com conversão para $\mathrm{kg} \mathrm{ha}^{-1}$.

A qualidade de fibra foi obtida por meio do equipamento HVI (High Volume Instruments) no laboratório da Embrapa Algodão, onde foram determinadas as seguintes características da fibra: percentagem, comprimento, uniformidade, índice de fibras curtas, resistência à ruptura, alongamento à ruptura, índice de micronaire, maturidade e índice de fiabilidade.

Os resultados foram submetidos à análise de variância ( $p>0,05)$ e, quando verificado efeito significativo, foram submetidos à análise de regressão polinomial por meio do software R (R core team, 2013). Para a escolha do modelo, foram considerados os valores do coeficiente de determinação $\left(\mathrm{R}^{2}\right)$ associado a cada modelo de regressão.

\section{RESULTADOS E DISCUSSÃO}

O diâmetro de caule, a altura de plantas e a área foliar foram influenciados pelos fatores isolados, bem como pela interação entre eles. Por sua vez, o número de capulhos por planta, a massa de frutos por planta, a produtividade de algodão em caroço, a produtividade de fibra de algodão, a resistência à ruptura e o índice de fibras curtas foram influenciados pelas populações de plantas. No entanto, o número de capulhos por metro quadrado, a percentagem de fibra, o comprimento de fibra, a uniformidade de comprimento, o alongamento à ruptura, o índice de micronaire e a maturidade não foram influenciados ( $\mathrm{p}$ > $0,05)$.

Durante os períodos de avaliação, o diâmetro de caule decresceu linearmente, à medida que se intensificou a competição intraespecífica (Figura 1a), evidenciando que aumentos da população de plantas causam redução do crescimento em espessura caulinar. Esses resultados corroboram os obtidos por Silva et al. (2006), que verificaram diminuição do diâmetro de caule com o aumento da população de plantas. 
Até os 30 dias após a emergência (DAE), não houve diferença significativa no crescimento em diâmetro caulinar das plantas de algodão. A partir dos 45 DAE, ocorreu rápido acúmulo de massa, sendo que, aos $75 \mathrm{DAE}$, houve estabilização do crescimento, a qual pode ser explicada pela partição dos fotoassimilados para o enchimento dos frutos (Heiffig et al., 2006), limitando o crescimento vegetativo.

A altura de plantas decresceu linearmente com o aumento da população de plantas durante os períodos de avaliação, sendo que as maiores alturas foram obtidas nas menores populações de plantas (Figura 1b).

A população de 125.000 plantas ha ${ }^{-1}$ reduziu a altura, em média, em 20,85\%, em comparação com as alturas da população de 13.889 plantas ha-1 . Resultados semelhantes foram obtidos por Gwathmey \& Clement (2010), os quais comprovaram que o aumento da densidade de semeadura, de 8,3 para 17,6 plantas $\mathrm{m}^{-2}$, reduziu em $20,45 \%$ a altura de plantas de algodão.

A redução da altura de plantas, quando a cultura é submetida a maior competição intraespecífica, pode ser devida ao fato de o algodão não apresentar sensibilidade aos efeitos da qualidade da luz ou não detectar essa diferença, uma vez que, comumente, plantas submetidas à competição intraespecífica têm a capacidade de detectar a presença de plantas vizinhas, alterando seu crescimento, resultando em aumento do comprimento do caule (Merotto Jr. et al., 2002).

A área foliar não foi influenciada pela interação de população de plantas com época de avaliação até os 45 DAE. A partir dos 60 DAE, a área foliar foi reduzida linearmente com o aumento da população de plantas (Figura 1c). A maior população de plantas reduziu em $83,26 \%$ a área foliar por planta na cultura do algodão colorido BRS Safira, o que indica que as altas populações de plantas reduzem o potencial de assimilação de carbono pelas plantas individualmente, conforme discutido por Gwathmey \& Clement (2010).

A redução da área foliar pode limitar a produção, visto que ela está diretamente relacionada com o potencial de rendimento das plantas (Kunz et al., 2007; Heiffig et al., 2006), sendo importante que elas desenvolvam área foliar suficiente para manterem altas produtividades e equilibrar o crescimento e a produção.

O número de capulhos por planta decresceu acentuadamente, à medida que aumentou a população de plantas (Figura 2a). Resultados semelhantes foram obtidos por Iqbal et al. (2012), que relataram menor número de capulhos por plantas à medida que se aumentou a densidade de plantas para os três genótipos de algodão estudados nos dois ciclos. Também Iqbal \& Khan (2011), em trabalho semelhante, concluíram que a redução do espaçamento entre plantas na linha de semeadura causa redução do número de capulhos por planta.

O maior número de capulhos por planta ocorreu nas menores populações de plantas, enquanto menores números foram observados nas maiores populações, as quais reduziram em $83,9 \%$ a produção de capulhos, em comparação com a produção da menor população de plantas. Resultados semelhantes, em trabalho realizado por Ren et al. (2013), mostram que ocorre decréscimo do número de frutos por planta com o aumento da densidade de plantas.

Essa redução da produção de capulhos pode ser explicada pela menor disponibilidade de nutrientes, gás carbônico, espaço, luz e água para as plantas na maior população (Ferrari et al., 2008).

A massa de frutos por planta ajustou-se ao modelo linear e decresceu com o aumento da população de plantas (Figura 2b). A população de 125.000 plantas ha ${ }^{-1}$ foi capaz de reduzir em $85,53 \%$ a massa de frutos por planta, quando se compara com a massa da menor população de plantas, evidenciando o efeito negativo do acúmulo de massa pelos frutos em cada planta, quando as plantas foram submetidas a maior estresse.

Resultados semelhantes foram obtidos por SouzaSchlick et al. (2012), que, trabalhando com a cultura da mamoneira, em diferentes espaçamentos e populações de plantas, relataram que o aumento da população de plantas reduziu significativamente o número de racemos por planta, concluindo que essa redução é devida à maior competição entre as plantas, o que acarreta menor produção de estruturas reprodutivas.

A produtividade de algodão em caroço, em função das diferentes populações de plantas, ajustou-se ao modelo quadrático. A máxima produtividade, $4.771 \mathrm{~kg} \mathrm{ha}^{-1}$, foi estimada na população de 71.471 plantas ha-1 . Quando a cultura foi submetida a populações de plantas inferiores ou superiores a esse valor, ocorreu decréscimo da produtividade de algodão em caroço (Figura 3).

A redução da produtividade de algodão em caroço em altas populações de plantas pode ser atribuída à maior competição intraespecífica pelos fatores de crescimento, limitando a quantidade de nutrientes, tornando as plantas incapazes de manter a produção (Cardoso et al., 2004). Por outro lado, baixas populações impossibilitam o aproveitamento eficiente da área e ocasionam plantas com maior número de ramos vegetativos, em detrimento dos reprodutivos, reduzindo, assim, a produtividade.

Resultados diferentes foram obtidos por Silva et al. (2012), os quais, trabalhando com espaçamento entre linhas e populações de plantas em algodoeiro, concluíram que a densidade populacional não interfere na produtividade de caroço de algodão, mas, sim, o espaçamento entre linhas. Por outro lado, Iqbal et al. (2012) aferiram que a 
maior população $(6,6$ plantas por metro) proporcionou maior produtividade de algodão em caroço do que a menor população (2,2 plantas por metro).

A produtividade obtida de algodão em caroço foi superior à média da região Norte, estimada em $3.150 \mathrm{~kg} \mathrm{ha}^{-1}$
(CONAB, 2013), evidenciando o potencial da cultura como fonte geradora de renda para a região.

A produtividade de fibra de algodão foi influenciada pelas diferentes populações de plantas, tendo seus valores médios ajustados ao modelo de regressão quadrática,
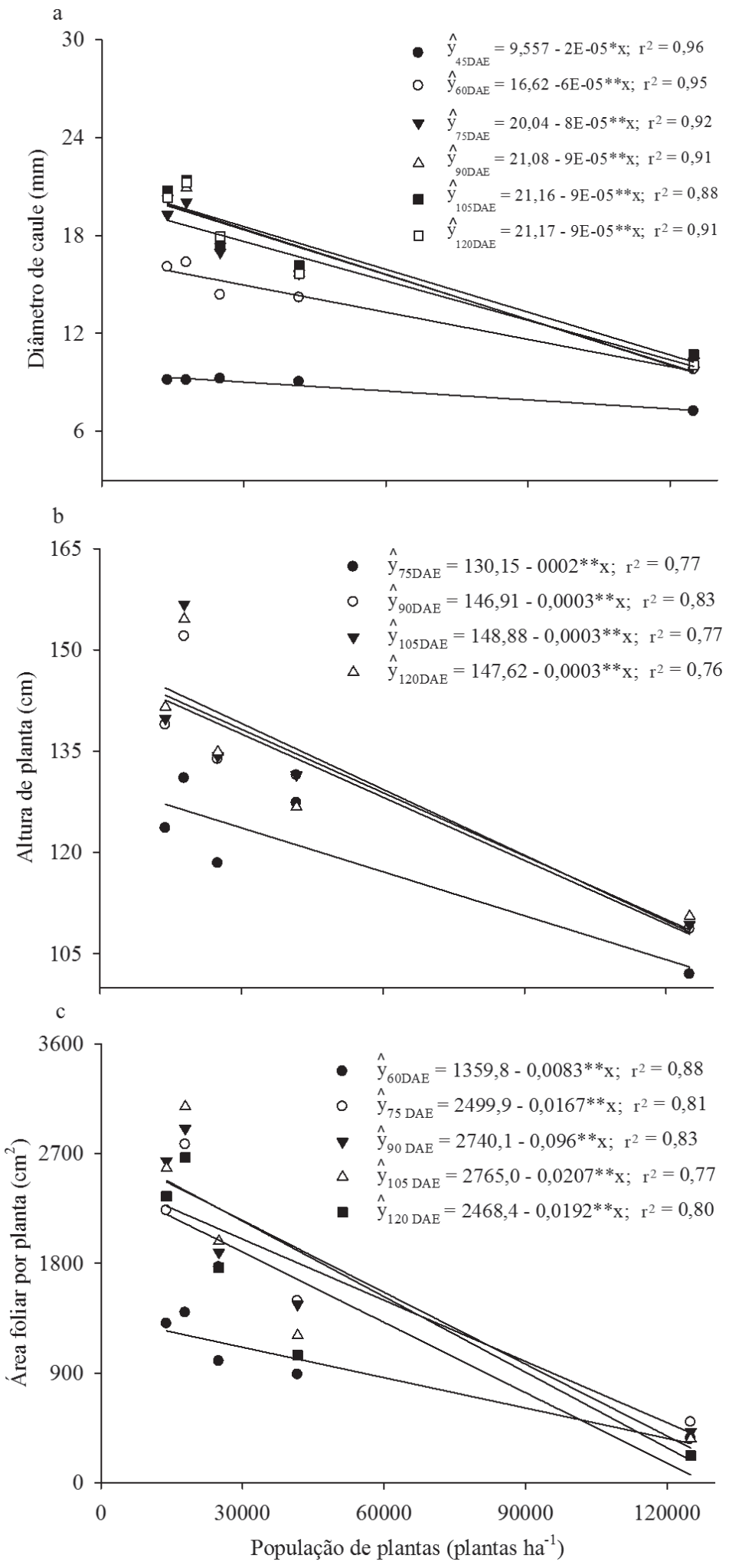

Figura 1: Diâmetro de caule (a), altura de plantas (b) e área foliar (c), ajustados em função de diferentes populações de plantas e dias após a emergência - DAE para a cultura de algodoeiro colorido, BRS Safira. 

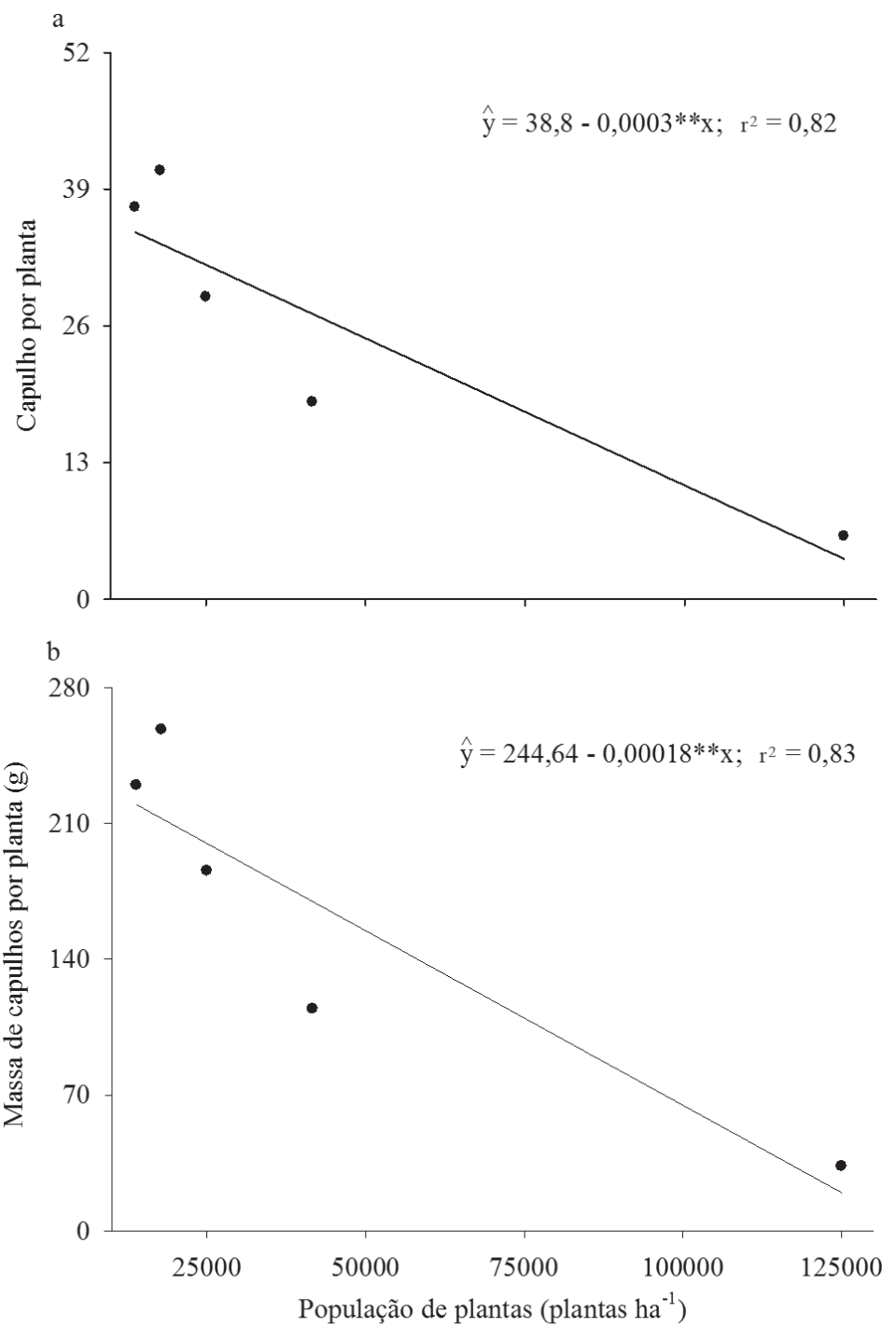

Figura 2: Número de capulhos (a) e massa de capulhos por planta (b), ajustados em função de diferentes populações de plantas na cultura de algodoeiro colorido, BRS Safira.

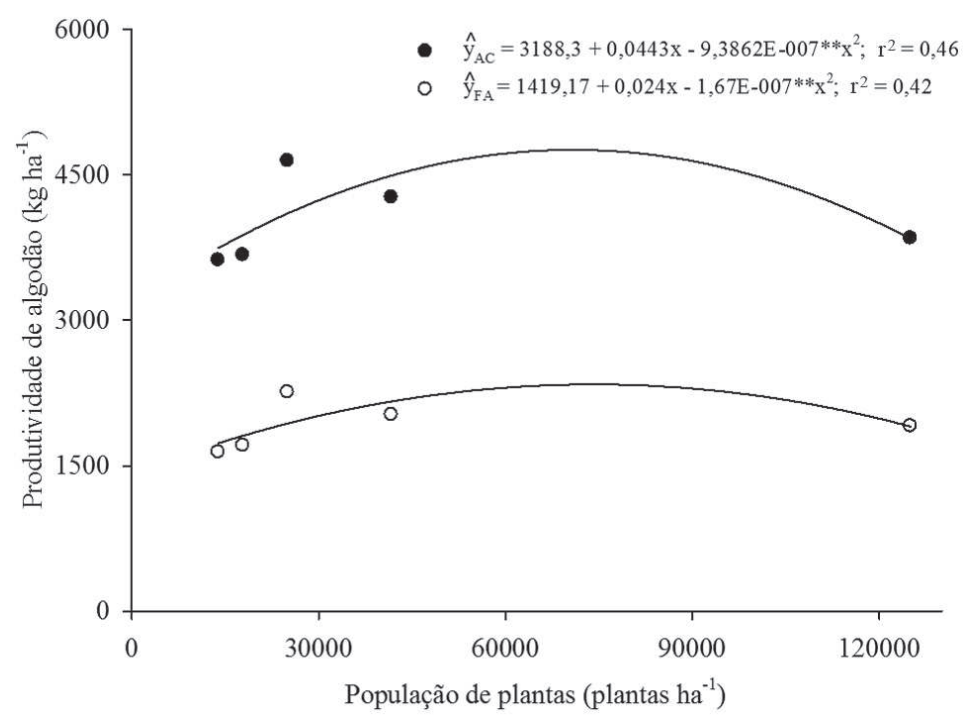

Figura 3: Produtividades de algodão em caroço (AC) e de fibra de algodão (FA), ajustadas em função de diferentes populações de plantas na cultura de algodoeiro colorido, BRS Safira. 
com ponto de máximo estimado na população de 72.964 plantas ha-1, (Figura 3), mostrando que altas populações de plantas podem reduzir o potencial produtivo da cultura do algodoeiro (Stephenson et al., 2011). A máxima produtividade estimada foi de $2.329 \mathrm{~kg} \mathrm{ha}^{-1}$ de fibra de algo- dão, superior à média da região Norte, que é de 1.197 kg ha $^{-1}$ (CONAB, 2013).

As menores produtividades de fibra nas menores populações podem ser atribuídas à baixa utilização dos recursos de crescimento, como radiação solar, resultando

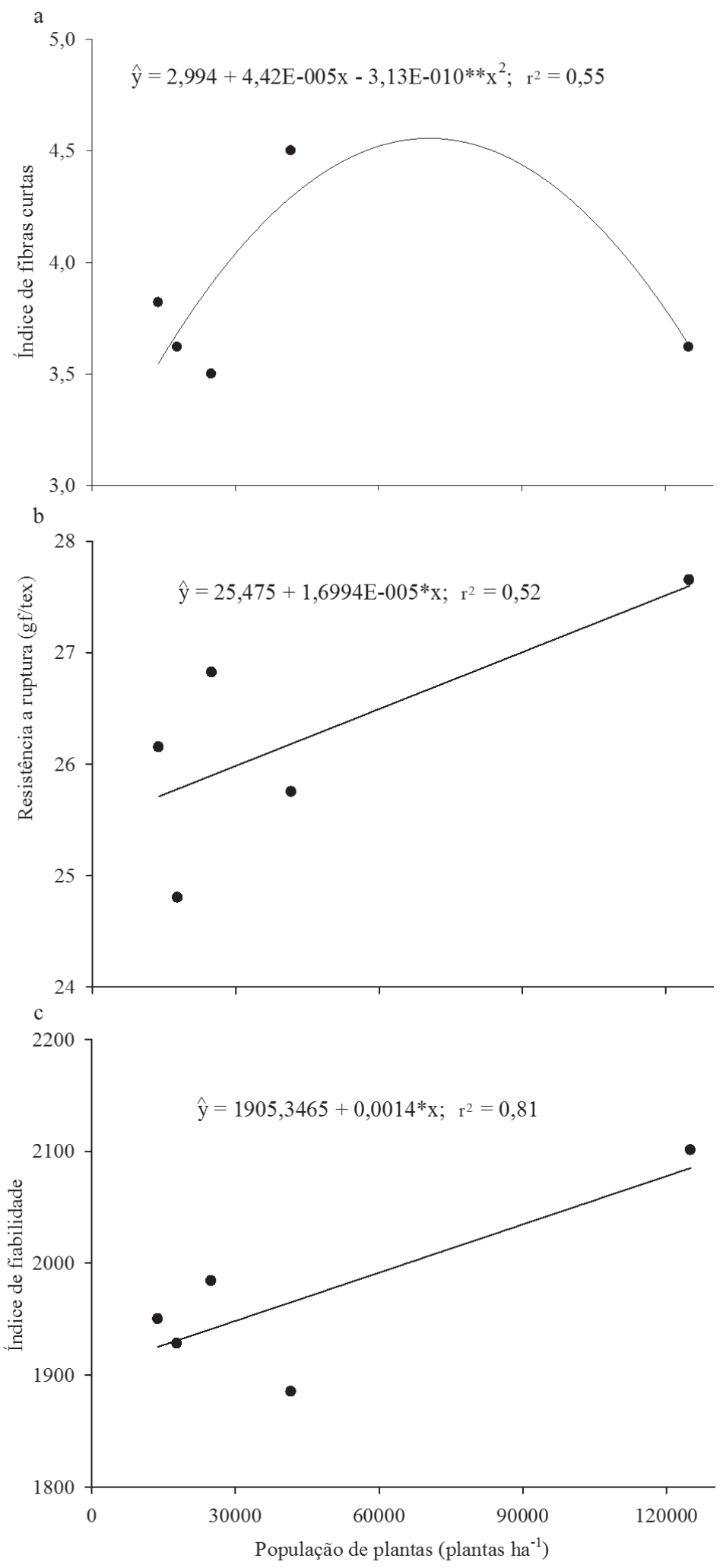

Figura 4: Índice de fibras curtas (a), resistência à ruptura (gf/tex) (b) e índice de fiabilidade (c), ajustados em função de diferentes populações de plantas na cultura de algodoeiro colorido, BRS Safira. 
em baixa produtividade. Assim, a maior produtividade na população de 72.964 plantas ha ${ }^{-1}$ pode ser devida a uma área foliar ideal, possibilitando melhor interceptação da radiação solar (Kaggwa-Asiimwe et al., 2013).

Mesmo com o decréscimo da produtividade de caroço e de fibra de algodão submetido a elevadas populações de plantas, nota-se a grande plasticidade da cultura, que foi capaz de se adaptar e de manter elevadas produtividades mesmo sob estresse competitivo, comprovando a existência de efeito compensatório do cultivar BRS Safira (Ferrari et al., 2008).

O índice de fibras curtas ajustou-se ao modelo quadrático e o maior valor obtido foi de 6,11 , na popula-

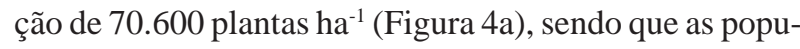
lações que proporcionaram as maiores produtividades de fibras geram fibras mais curtas. A resistência à ruptura ajustou-se ao modelo linear e foi crescente com o aumento da população de plantas, indicando que altas densidades populacionais não interferem na resistência da fibra (Figura 4b).

O índice de fiabilidade ajustou-se ao modelo quadrático e o menor valor obtido foi de 1.792 , na população de 53.185 plantas ha ${ }^{-1}$, mostrando que esta característica é melhorada com o aumento da população de plantas, sendo os melhores resultados obtidos na população de 125.000 plantas ha-1 (Figura 4c).

Resultados diferentes foram obtidos por Cardoso et al. (2004), que, trabalhando com populações ultraadensadas de algodão, concluíram que as diferentes densidades populacionais não influenciam as características das fibras, o que também foi obtido por Stephenson et al. (2011), que, trabalhando com diferentes espaçamentos entre plantas e entre linhas na cultura do algodoeiro, concluíram que os tratamentos estudados não afetam as características das fibras.

\section{CONCLUSÕES}

O aumento da população de plantas provoca mudanças morfológicas na cultura do algodoeiro, como a redução no diâmetro de caule, da altura de plantas, da área foliar, do número de frutos e da massa de frutos por planta, mas não influencia o número de capulhos por metro quadrado.

Ocorre redução da produtividade de algodão em caroço e de fibra de algodão, nas maiores e nas menores populações de plantas, e as maiores produtividades de algodão em caroço e de fibra de algodão foram obtidas nas populações de 71.471 e 72.964 plantas ha-1 $^{-1}$, respectivamente.

As características tecnológicas de fibra, índice de fibras curtas, resistência à ruptura e o índice de fiabilidade, são melhoradas com o cultivo de 125.000 plantas ha ${ }^{-1}$.

\section{AGRADECIMENTOS}

Os autores agradecem à Embrapa Algodão, ao Centro Universitário Luterano de Ji-Paraná-RO (CEULJI/ULBRA) e ao Conselho Nacional de Desenvolvimento Científico e Tecnológico (CNPq).

\section{REFERÊNCIAS}

Bezerra RB, Dantas RT \& Trindade AG (2010) Caracterização temporal da precipitação pluvial do município de Porto Velho/ RO no período de 1945 a 2003. Sociedade \& Natureza, 22:609623.

Cardoso GD, Beltrão NEM, Pereira JR, Gondim TMS \& Bruno RL (2004) Produtividade e características da fibra de algodão plantado em população ultra-adensada. Revista Brasileira de Oleaginosas e Fibrosas, 8:831-838.

CONAB - Companhia Nacional de Abastecimento (2013) Acompanhamento da Safra Brasileira de Grãos 2012/2013, Décimo Primeiro Levantamento, Agosto de 2011. Brasília: CONAB, 29p.

Darawsheh MK, Khah EM, Aivalakis G, Chachalis D \& Sallaku F (2009) Cotton row spacing and plant density cropping systems I. Effects on accumulation and partitioning of dry mass and LAI. Journal of Food Agriculture \& Environment, 7:258-261.

Ferrari S, Furlani Júnior E, Ferrari JV, Santos ML \& Santos DMA (2008) Desenvolvimento e produtividade do algodoeiro em função de espaçamentos e aplicação de regulador de crescimento. Acta Scientiarum Agronomy, 30:365-371.

Guaratini CCI \& Zanoni MV (2000) Corantes têxteis. Química Nova, 23:71-78.

Grimes DW \& Carter LM (1969) A linear rule for direct non destrutive leaf area measurements. Agronomy Journal, 61:477479 .

Gwathmey CO \& Clement JD (2010) Alteration of cotton sourcesink relations with plant population density and mepiquat chloride. Field Crops Research, 116:101-107.

Heiffig LS, Câmara GMS, Marques LA, Pedroso DB \& Piedade SMS (2006) Fechamento e índice de área foliar da cultura da soja em diferentes arranjos espaciais. Bragantia, 65:285-295.

Iqbal M \& Khan MA (2011) Response of cotton genotypes to planting date and plant spacing. Frontiers of Agriculture in China, 5:262-267.

Iqbal M, Ahmad S, Nazeer W, Muhammad T, Khan BM, Hussain M, Mehmood A, Tauseef M, Hameed A \& Karim A (2012) High plant density by narrow plant spacing ensures cotton productivity in elite cotton (Gossypium hirsutum L.) genotypes under severe cotton leaf curl virus (CLCV) infestation. African Journal of Biotechnology, 11:2869-2878.

Kaggwa-Asiimwe R, Andrade-Sanchez P \& Wang G (2013) Plant architecture influences growth and yield response of upland cotton to population density. Field Crops Research, 145:52-59.

Kunz JH, Bergonci JI, Bergamaschi H, Dalmago GA, Heckler BMM \& Comiran F (2007) Uso da radiação solar pelo milho sob diferentes preparos do solo, espaçamento e disponibilidade hídrica. Pesquisa Agropecuária Brasileira, 42:1511-1520.

Merotto Jr. A, Vidal RA, Fleck NG \& Almeida ML (2002) Interferência das plantas daninhas sobre o desenvolvimento inicial de plantas de soja e arroz através da qualidade da luz. Planta Daninha, 20:09-16.

Pereira R, Ferreira IC \& Cassia MT (2011) Perdas na colheita mecanizada de algodão. Scientia Agropecuaria, 2:07-12. 
Ren X, Zhang L, Du M, Evers JB, Werf WVD, Tian X \& Li Z (2013) Managing mepiquat chloride and plant density for optimal yield and quality of cotton. Field Crops Research, 149:01-10.

$\mathrm{R}$ core team (2013) R: A language and environment for statistical computing. Vienna, R Foundation for Statistical Computing. Disponível em: <http://www.R-project.org/>. Acessado em: 10 de dezembro de 2013.

Rosolem CA (2007) Fenologia e ecofisiologia no manejo do algodoeiro. In: Freire EC (Ed.) Algodão no cerrado do Brasil. Brasília Associação Brasileira dos Produtores de Algodão. p.649-688.

Santos HG, Jacomine PKT, Anjos LHC, Oliveira VA, Lubreras JF, Coelho MR, Almeida JA, Cunha TJF \& Oliveira JB (2013) Sistema Brasileiro de Classificação de Solos. $3^{\mathrm{a}}$ ed. Brasília, Embrapa. 353p.
Silva AV, Chiavegato EJ, Carvalho LH \& Kubiak DM (2006) Crescimento e desenvolvimento do algodoeiro em diferentes configurações de semeadura. Bragantia, 65:407-411.

Silva PT, Macedo FG, Camacho MA, Santos C, Santi A, Krause W \& Rambo JR (2012) Spacing and plant density effect on reproductive development of herbaceous cotton. Scientia Plena, 8:01-08.

Souza-Schlick GD, Soratto RP, Bottino D \& Fernandes AM (2012) Crescimento e produtividade da mamona de porte baixo em diferentes espaçamentos e populações de plantas. Interciência, 37:49-54.

Stephenson DO, Barber T \& Bourland FM (2011) Effect of twinrow planting pattern and plant density on cotton growth, yield, and fiber quality. Journal of Cotton Science, 15:243-250. 